\title{
Reseñas • Reseñas • Reseñas • Reseñas
}

NÚÑEZ, G.

Historia de la educación lingüística y
literaria

Madrid: Marcial Pons, 2016

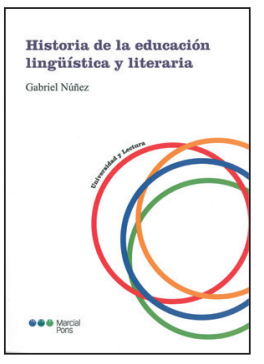

Ante todo intentaré esbozar un breve relato sobre el significado y las aportaciones de esta Historia para quienes cursamos estudios de Filología Hispánica y estamos habituados sobre todo a practicar la actividad intelectual que resulta del hecho de trabajar con dos disciplinas, Historia y Literatura, que han mantenido una relación tan conflictiva como prolongada a lo largo del tiempo. En este volumen, además, se combinan ambas con Lengua y se contextualizan mediante su inserción en el moderno sistema escolar con objeto de poder así analizar la Historia de la educación lingüística y literaria en la España contemporánea. Con tal fin, debemos añadir a los problemas relacionados con la historia de dichas disciplinas, que la cultura moderna aproximó para poder abordarlas teórica y técnicamente con éxito, aquellos otros que tienen que ver con la revisión diacrónica del modo en que hemos aprendido en las aulas la lengua y la literatura, así como con las practicas institucionales que han configurado tal Historia de la educación lingüística y literaria.
Y debo confesar que, dada la casi ausencia de formación didáctica existente en los cursos de humanidades, lo primero que llamó mi atención fue el análisis de los modelos de educación lingüística y literaria existentes a lo largo del tiempo en España; así como los límites cronológicos y conceptuales a partir de los que se perfila la primera Historia de la Literatura en España, la de Gil de Zárate, sobre todo si se la pone en relación con esta otra primera Historia. Al leer ambas he comprendido en su sentido pleno el aserto que tantas veces he oído de viva voz al maestro Juan Carlos Rodríguez: únicamente el vacío de historia ha hecho posible el nacimiento de las modernas disciplinas positivas. Los institucionistas lo explicaron de un modo más sencillo, aunque no menos certero: si construimos un sujeto dotado de razón cartesiana, por un lado; y si creamos asignaturas positivas -la psicología, la historia, la literatura, la sociología, etc.- que analicen el mundo o la vida toda mediante nociones parceladas y circunscritas al campo teórico de cada una de ellas, ya tendremos el sujeto que conoce y los objetos de estudio sobre los que perfilar los campos conceptuales propios de cada una de estas; es decir, si la vida toda debe ser objeto de las ciencias positivas, esta, la vida, debe también ser parcelada en ámbitos diversos para poder conocerla adecuadamente. Pues bien, aquí radica el salto cualitativo que se da en esta Historia: no solo se analizan tales disciplinas positivas en su historia y en sus aplicaciones didácticas, 
sino que se interpreta la función ideológica que estas han cumplido en la España contemporánea. Así entendida, la primera, sería una historia positivista pensada para crear la conciencia nacional de los escolares que la estudiaban mediante la lectura de los grandes escritores de nuestra historia con los que debíamos sentirnos orgullosos de pertenecer a dicha tradición cultural; en tanto que esta nueva historia inserta tales autores y sus obras en dicha tradición cultural y enjuicia el papel que han jugado en la construcción de nuestro imaginario cultural y en nuestra formación histórica, estética e ideológica.

Además, se abordan en esta Historia algunos de los aspectos velados de nuestra modernidad intelectual; por ejemplo: se describe la manera en que los institucionistas, percatados de los excesos nacionalistas de este modelo, implantan otra disciplina, la Estética, con el fin de inculcar una moral laica a sus alumnos, porque están firmemente convencidos de que solo así se podrá dar un giro ideológico a una juventud ruda, de costumbres vulgares y habla soez, nacionalista hasta el extremo de admirar el carlismo y poco refinada en sus maneras y en sus hábitos sociales. Ellos creen que otro modelo educativo, el vigente en la ILE, con un currículum cíclico y una enseñanza integral que incluye las humanidades clásicas, las humanidades modernas y las ciencias, entre otras disciplinas tales como el derecho, el deporte o el periodismo, será el mejor modo de lograr una juventud democrática y reformista, que profese el credo liberal en una sociedad a la que Larra, entre otros, había aplicado la piqueta para intentar modernizarla y pasar la página del libro de los errores cometidos.
Con respecto a la historia de la educación lingüística, en este ensayo se estudian los cuatro grandes modelos en los que hemos sido educados los escolares del sistema público de enseñanza en la España contemporánea: el modelo retórico, el modelo basado en el conocimiento sistemático de la lengua, el comunicativo y el intercultural, así como los manuales escolares a través de los cuales se trasladan a las aulas los contenidos fundamentales de dichos modelos.

En relación con la lectura, recordemos que de entre todas las actividades que realizamos a lo largo de nuestra vida tal vez ninguna sea tan civilizadora como la lectura. O, cuando menos, podríamos admitir que la educación familiar y escolar que ha primado en el sistema educativo de la Modernidad nos ha ayudado a alcanzar un logro magistral: nos enseñó a leer de acuerdo con una ética y una estética a través de la cual se nos inculca la ideología burguesa de los sujetos libres; ignorando en cambio que la literatura también forma parte de las relaciones sociales. Así se fundieron los valores dominantes con el inconsciente de los escolares de las distintas clases sociales. Leer y aprender leyendo ha sido el modo de construir el yo moral y estético ideado por la burguesía ilustrada. Esta era una lectura civilizadora del yo y de la vida, frente a la lectura exterminadora que, por ejemplo, hicieron los nazis con respecto al pueblo judío al practicar con él la solución final.

Pero esta lectura también tenía un envés: nos hacía ver que aquel yo nunca era un yo ideal, o al menos no era el yo que queríamos alcanzar, pudiendo derivar en otras lecturas del yo y del mundo más próximas a las que hicieron Brech o Marx; 
lecturas, por un lado, capaces de reflexionar sobre las trampas de ese yo construido a partir del inconsciente ideológico y libidinal de la burguesía occidental y, por otro, lecturas capaces de enseñarnos a "leer desde la explotación", en nombre de los desfavorecidos. La distancia ente ambos modos de leer es abismal. Y esta sería, como bien explica Juan Carlos Rodríguez en el prólogo del libro Cómo nos enseñaron a leer, una de las misiones de la lectura actual: saber escribir y saber leer desde dentro de ese inconsciente ideológico y libidinal pero para romper con ellos, es decir, para intentar construir una lectura y una vida en libertad y sin explotación. Con tal fin, en este volumen se responden dos preguntas: Cómo nos enseñaron a leer y cómo aprendimos a leer el mundo a partir de nuestras lecturas literarias.

En fin, no debemos olvidar que estamos ante una Historia fundacional, como lo fue la de Gil de Zárate para la Historia de la Literatura, necesaria para recuperar la memoria histórica y para no seguir creando sobre el vacío historiográfico y educacional en el que nos movemos.

Gabriel Núñez Molina

Universidad de Almería 